\title{
Microstructure and Tribological Properties of PTA Deposited Stellite 12 Coating on Steel Substrate
}

\author{
Amir Motallebzadeh ${ }^{1, *}$, Erdem Atar $^{2}$, Huseyin Cimenoglu ${ }^{1}$ \\ ${ }^{1}$ Department of Metallurgical and Materials Engineering, Istanbul Technical University, Turkey \\ ${ }^{2}$ Department of Materials Science and Engineering, Gebze Technical University, Turkey
}

Copyright $(\mathcal{C} 2015$ by authors, all rights reserved. Authors agree that this article remains permanently open access under the terms of the Creative Commons Attribution License 4.0 International License

\begin{abstract}
The present work studies microstructure and wear resistance of Stellite 12 alloy coating deposited on quenched and tempered AISI 4140 steel substrate using plasma transferred arc (PTA) hardfacing method. The X-ray diffraction, scanning electron microscopy (SEM) micrographs and energy-dispersive X-ray (EDX) analysis indicated that Stellite12 mainly consists of solid solution phase $(\alpha-\mathrm{Co}, \varepsilon-\mathrm{Co})$, chromium-rich carbides $\left(\mathrm{Cr}_{7} \mathrm{C}_{3}, \mathrm{Cr}_{23} \mathrm{C}_{6}\right)$ and tungsten-containing compounds. The wear properties of PTA hardfaced stellite12 comparing with AISI 4140 steel at room temperature (RT) were investigated by using the ball-on-disc type tribotester. It has been found that the Stellite12 hardfacing coating exhibits superior wear resistance than substrate during dry sliding wear test at RT.
\end{abstract}

Keywords Sliding Wear, Hardfacing Alloy, Stellite12, PTA

\section{Introduction}

Hardfacing is a technique used to enhance surface properties of metallic components under harsh conditions of aerospace, gas turbines, petrochemical, mining industries and power plants [1, 2]. Multicomponent $\mathrm{Co}, \mathrm{Ni}$ and Fe-based alloys are homogeneously deposited on the surface of a soft material (carbon and low alloy steels) by welding or cladding, with the purpose of increasing hardness, wear and corrosion resistance without significant loss in ductility and toughness of the substrate. Several arc welding techniques such as gas metal arc welding (GMAW), shielded metal arc welding (SMAW), submerged arc welding (SAW), gas tungsten arc welding (GTAW) and plasma transferred arc welding (PTA) and laser cladding can be used for hardfacing [1]. Plasma transferred arc welding (PTA) represents a very good alternative to other surface welding processes. It has advantages over conventional welding techniques in terms of its high deposition rate, lower heat input, excellent arc stability and most importantly the wide range of choices of materials. It also have advantages over laser cladding because of its lower capital and maintenance costs, higher thickness capability, higher deposition efficiency and rate, and ease of integration into certain production settings due to its small size [2-4]. Stellite hardfacing alloys derived from the $\mathrm{Co}-\mathrm{Cr}-\mathrm{W}-\mathrm{C}$ type can be found in several modifications and commercial grades such as Stellite1, 12 and 6. [3]. The hardness and tribological properties of Stellite alloys at room temperature depends on strengthening and crystallographic nature of cobalt-rich solid solution, type and amount of carbides and intermetallic compounds formed during solidification [4]. In these alloys, carbides are considered as the primary strengthening agent while solid solution hardener including chromium and tungsten are considered as the secondary strengthening agent [5]. The present investigation aims to study microstructure, chemical composition, hardness and sliding wear of Stellite 12 alloy.

\section{Materials and Methods}

Stellite 12 coating powder with particle size of 76 to 150 $\mu \mathrm{m}$ were deposited on quenched and tempered AISI 4140 steel by PTA welding machine. The nominal composition of the Stellite12 alloy powder and AISI 4140 steel is listed in Table 1 and Table 2.

Table 1. Nominal composition of Stellite 12 powder [wt $\%]$.

\begin{tabular}{|c|c|c|c|c|c|c|c|}
\hline $\mathrm{Co}$ & $\mathrm{Cr}$ & $\mathrm{C}$ & $\mathrm{W}$ & $\mathrm{Ni}$ & $\mathrm{Si}$ & $\mathrm{Fe}$ & $\mathrm{Mn}$ \\
\hline Balance & 29.54 & 1.65 & 8.50 & 2.21 & 1.52 & 2.43 & 0.98 \\
\hline
\end{tabular}

Table 2. Nominal composition of AISI 4140 steel [wt $\%$ ].

\begin{tabular}{|c|c|c|c|c|c|c|c|}
\hline $\mathrm{Fe}$ & $\mathrm{C}$ & $\mathrm{Cr}$ & $\mathrm{Mn}$ & $\mathrm{S}$ & $\mathrm{P}$ & $\mathrm{Mo}$ & $\mathrm{Si}$ \\
\hline Balance & 0.38 & 0.93 & 0.85 & 0.01 & 0.02 & 0.21 & 0.22 \\
\hline
\end{tabular}



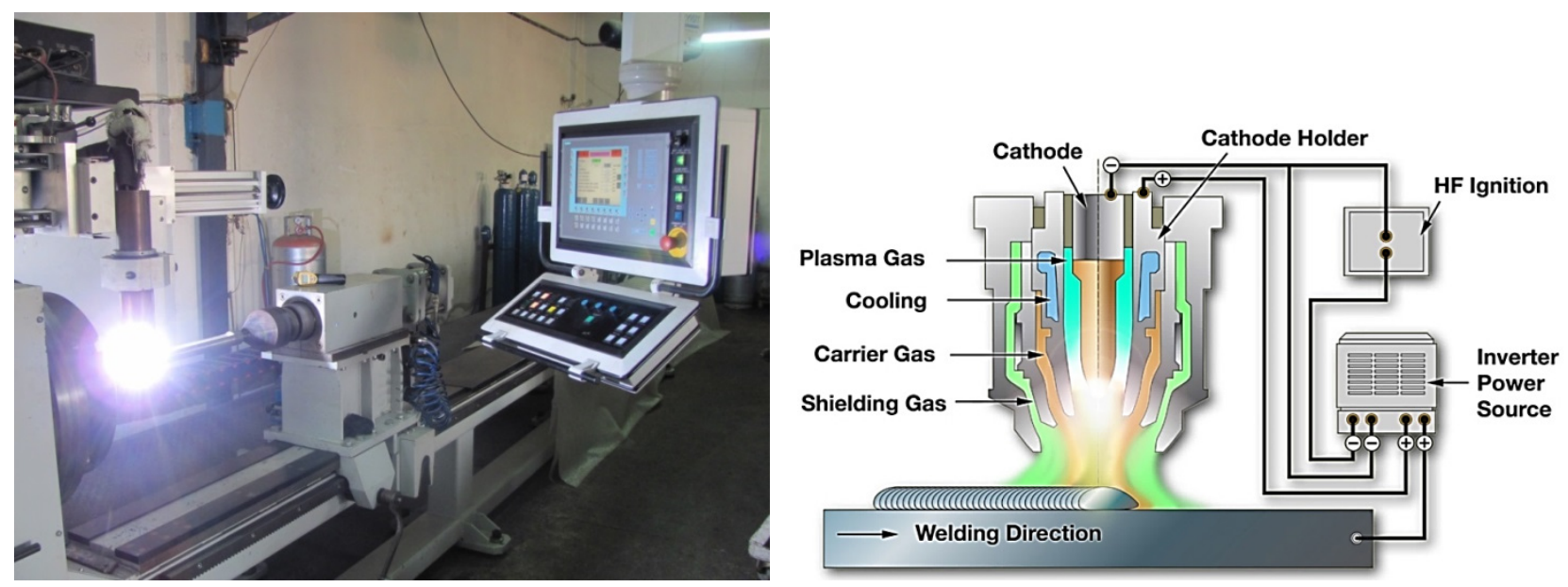

Figure 1. An overall view and schematic of the PTA process used for deposition hardfacing layer [6].

The PTA deposition process was implemented under constant parameters which were a current of $92 \mathrm{~A}$, a voltage of $32 \mathrm{~V}$ and a travel speed of $85 \mathrm{~mm} / \mathrm{min}$. Deposition procedures were carried out in a single layer with a thickness of $5 \mathrm{~mm}$. An overall view and schematic of PTA process used for deposition hardfacing layer are depicted in Fig. 1. In the PTA process the powder is continuously transported from the hopper through flexible tubes to the torch by an inert carrier gas and introduced into the plasma arc and heated and accelerated to the substrate surface. Transferred arc produces the energy density needed to melt both the base metal and the feedstock materials. A molten pool formed on the surface of substrate is protected against oxidative atmosphere by a curtain of active or inert gas as shielding gas.

After PTA deposition, the surfaces of specimen were ground to make a flat hardfacing layer with a thickness of 2.5 $\mathrm{mm}$ for characterization and wear test. Phase analysis and microstructure were examined by X-ray diffractometer (XRD) with $\mathrm{Cu}-\mathrm{Ka}$ radiation (GBC, Australia) and field emission scanning electron microscope (SFEG SEM, Philips, Holland) equipped with energy dispersive X-ray (EDX) spectrometer. Surface of samples for wear and hardness tests were ground with $\mathrm{SiC}$ papers and polished with $0.25 \mu \mathrm{m}$ diamond paste in order to remove surface roughness effect. To determine the hardness of the samples, conventional micro-hardness tester (Shimadzu, HMV2, Japan) with indentation load of $500 \mathrm{~g}$ was used on the surface of samples and ten tests were carried out on each specimen and the average was the final result of hardness. Dry sliding wear tests were performed using a ball-on-disc type tribometer (CSM Tribotester, Switzerland) under normal load of $3 \mathrm{~N}$ at RT. A ball made of alumina $\left(\mathrm{Al}_{2} \mathrm{O}_{3}\right)$ with diameter of $6 \mathrm{~mm}$ was used to wear samples with a constant sliding speed of 0.1 $\mathrm{m} / \mathrm{s}$ along a circular path of $5.5 \mathrm{~mm}$ in radius for the total sliding distance of $500 \mathrm{~m}$. The test procedure involved ultrasonically cleaning the specimens in acetone. During wear testing, friction coefficient data was continuously recorded. After the wear tests, wear tracks were analyzed by using a contact type profilometer (Dektak-6M, Veeco, USA) and the worn surfaces were examined by a SEM.

\section{Results and Discussion}

Characterization. The X-ray diffraction pattern of PTA deposited Stellite 12 alloy is presented in Fig. 2. In this figure, the X-ray pattern reveals that the cobalt solid solution is a mixture of $\alpha$-Co and $\varepsilon$-Co phases, and includes carbides such as $\mathrm{Cr}_{7} \mathrm{C}_{3}$ and $\mathrm{Cr}_{23} \mathrm{C}_{6}$. Fig. 3 shows the cross sectional SEM micrograph and EDX elemental map of PTA deposited Stellite 12. Three phases can be distinguished by elemental contrast. Stellite 12 sample has a eutectic microstructure consisting of carbides and tungsten-containing compounds dispersed into the dendritic cobalt-rich solid solution matrix. The EDX mapping and compositional evolution of each phase in the microstructures of Stellite 12 are presented in Table 3. The dendrite phase consists of cobalt-rich solid solution that contains chromium, tungsten and nickel and diluted iron. The carbide is found to contain higher chromium concentration, and therefore are $\mathrm{Cr}_{7} \mathrm{C}_{3}$ and $\mathrm{Cr}_{23} \mathrm{C}_{6}$ phases containing cobalt and tungsten which take the place of chromium. However difference between $\mathrm{Cr}_{7} \mathrm{C}_{3}$ and $\mathrm{Cr}_{23} \mathrm{C}_{6}$ carbides are not readily distinguishable under a microscope. Tungsten-containing compound has mainly cobalt and chromium in its structure but because of low amount of these phases in Stellite 12 alloy their peak are not obvious in XRD analysis. Stellite 12 alloy with carbon contents less than about 2 wt $\%$ exhibit a hypo-eutectic microstructure. The primary solidified phase in this alloy consists of a cobalt-rich solid solution with FCC $(\alpha-\mathrm{Co})$ and HCP ( $\varepsilon-\mathrm{Co})$ crystal structure. There are two allotropic modifications of pure cobalt: a hexagonal close-packed (HCP), stable at temperatures below $422^{\circ} \mathrm{C}$, and a face-centered-cubic (FCC), which is stable between $422^{\circ} \mathrm{C}$ and its melting point of $1495^{\circ} \mathrm{C}$ [7]. When alloying elements are present, the 
transformation temperatures may be affected [8]. While $\mathrm{W}$ and Mo tend to increase the transformation temperature, presence of $\mathrm{Ni}$ and $\mathrm{Fe}$ tend to decrease the transformation temperature and increasing metastable FCC phases in microstructure. However, under most cooling conditions, the transformation tends to be sluggish in a cobalt-based alloy, therefore the cobalt matrix is a mixture of $\varepsilon$ and metastable $\alpha$ at room temperature. The eutectic structure consists of cobalt-rich phase mixed with chromium-rich carbides $\left(\mathrm{Cr}_{7} \mathrm{C}_{3}\right.$, $\left.\mathrm{Cr}_{23} \mathrm{C}_{6}\right)$, tungsten-containing complex carbides $\left(\mathrm{Co}_{3} \mathrm{~W}_{3} \mathrm{C}\right.$, $\left.\mathrm{Co}_{6} \mathrm{~W}_{6} \mathrm{C}\right)$ and intermetallic compounds $\left(\mathrm{Co}_{3} \mathrm{~W}, \mathrm{Co}_{7} \mathrm{~W}_{6}\right)$.

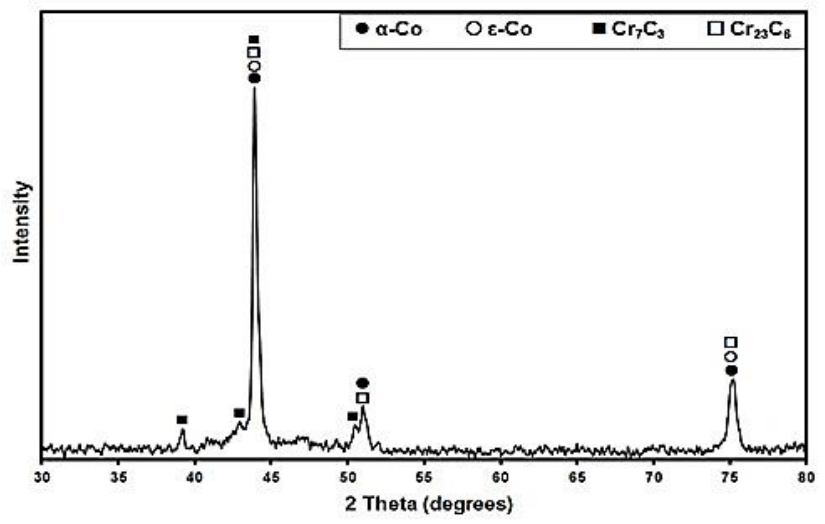

Figure 2. XRD pattern of the PTA deposited Stellite 12.

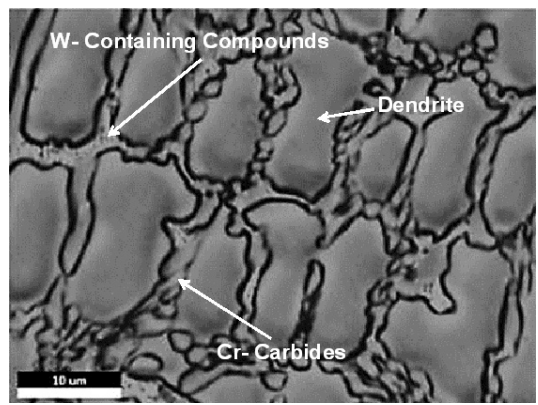

Srellite12

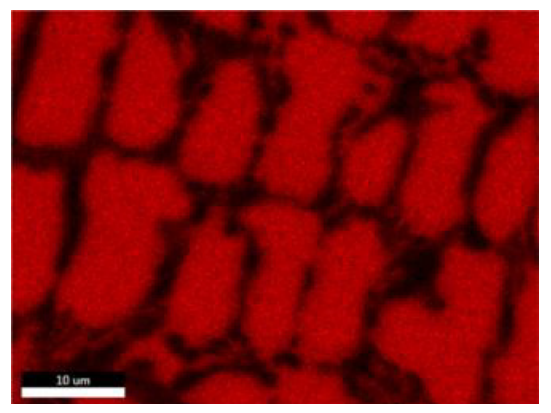

Co

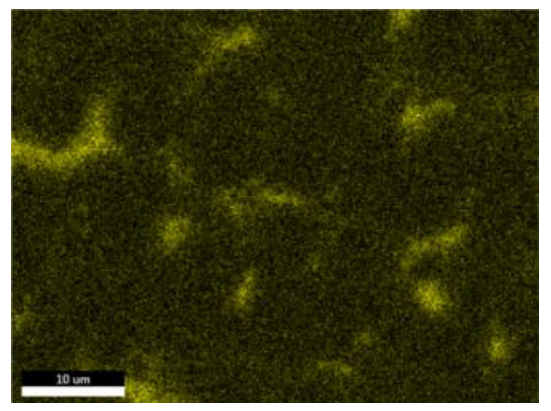

W

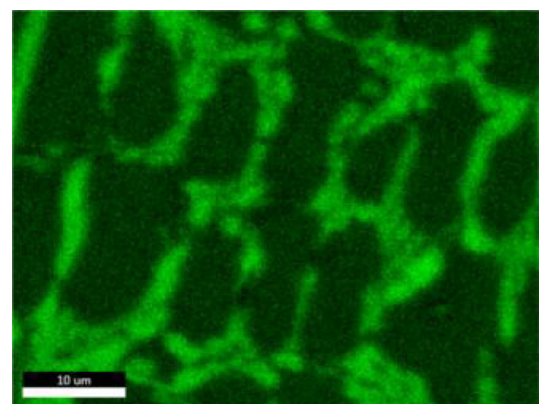

$\mathrm{Cr}$

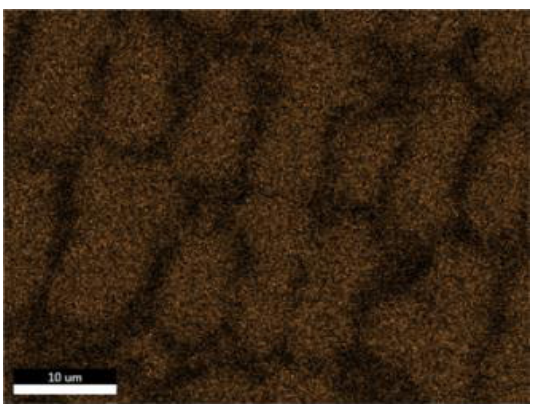

$\mathrm{Ni}$

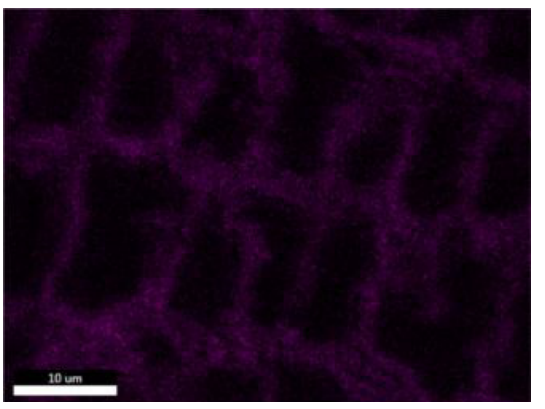

C

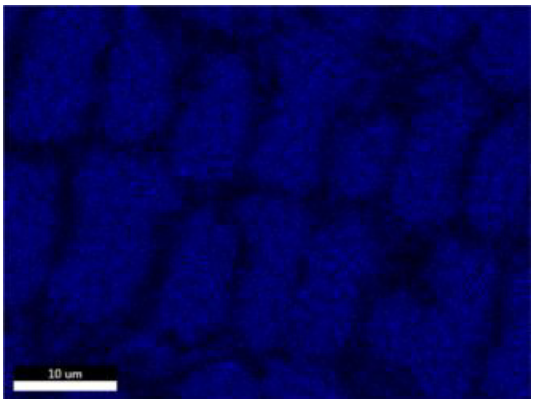

$\mathrm{Fe}$

Figure 3. SEM micrograph and EDX elemental map of cross-section of PTA deposited Stellite 12. 
Table 3. Chemical compositions of dendrite phase, eutectic carbides and compounds in the PTA deposited Stellite 12 alloy measured by EDX.

\begin{tabular}{|c|c|c|c|c|c|c|c|c|c|c|}
\hline & \multicolumn{2}{|c|}{ Co } & \multicolumn{2}{|c|}{$\mathrm{Cr}$} & \multicolumn{2}{|c|}{ W } & \multicolumn{2}{|c|}{$\mathrm{Ni}$} & \multicolumn{2}{|c|}{$\mathrm{Fe}$} \\
\hline & $\mathrm{wt} \%$ & at $\%$ & $\mathrm{wt} \%$ & at $\%$ & $\mathrm{wt} \%$ & at $\%$ & $\mathrm{wt} \%$ & at $\%$ & wt $\%$ & at $\%$ \\
\hline Dendrite & 63.24 & 63.40 & 23.87 & 27.12 & 5.48 & 1.76 & 2.15 & 2.17 & 5.26 & 5.55 \\
\hline Cr-Carbides & 21.75 & 21.01 & 69.74 & 76.35 & 8.51 & 2.64 & --- & --- & --- & --- \\
\hline W- Compounds & 37.87 & 46.44 & 29.23 & 40.63 & 32.90 & 12.93 & --- & --- & --- & --- \\
\hline
\end{tabular}

The results of the hardness measurements conducted on the surfaces of AISI 4140 steel and Stellite 12 are 320 and $490 \mathrm{HV}$ respectively. Higher hardness of Stellite 12 alloy can be attributed to the formation of carbides and intermetallic during solidification. The hardness of tungsten-containing compounds and chromium-rich carbides vary between 1420 to $1700 \mathrm{HV}$ and 880 to $1030 \mathrm{HV}$ respectively [3].

Wear. Width and depth of wear tracks, volume loss and friction coefficient of AISI 4140 steel and PTA deposited Stellite 12 hardfacing alloy at room temperature are presented in Table 4. Friction coefficients of tested samples were obtained from the steady state values of friction coefficient curves presented in Fig. 4. For each wear track, eight different locations were measured by contact type profilometer system and the software calculated the cross-sectional area automatically. The average of the eight cross-sectional areas was multiplied by the circular length of the wear track to obtain the volume of the wear track. It is clear that Stellite 12 is more wear resistance than AISI 4140 steel at room temperature. To gain further insight into the wear mechanisms, the worn surfaces of the samples were examined by SEM (Fig. 5). Fig. 5(a) shows that the wear track of AISI 4140 steel exhibited a roughened appearance. Grooves in the direction of sliding that are induced by the microploughing action indicate the abrasive is dominant wear mechanism at room temperature. The worn surfaces of the Stellite 12 coating tested at RT can be characterized by accumulated plastic deformation resulting from cyclic sliding contact (Fig. 5(b)). Therefore plastic deformation was determined as main wear mechanism of Stellite12 alloy at RT $[9,10]$. The wear resistance properties of Stellite alloys at room temperature are associated to higher hardness and Young's modulus of solid solution as well as the large volume fraction of carbides and intermetallic phases. Also metastable FCC phase tends to transform to a HCP phase under the action of a mechanical stress (or strain) at room temperature [10]. FCC to HCP transformation is classified as martensitic, arising from the mobility of partial dislocations along the close-packed planes. Therefore this allotropic transformation increases the alloy's work hardening rate, which is reported to be beneficial for sliding wear resistance of Stellite alloys [11-13].

Table 4. Volume loss and friction coefficient of AISI 4140 steel and Stellite 12 hardfacing alloy at RT.

\begin{tabular}{|c|c|c|c|c|}
\hline & Width $(\mu \mathrm{m})$ & Depth $(\mu \mathrm{m})$ & $\begin{array}{c}\text { Volume Loss } \\
\left(\mathrm{mm}^{3}\right) \times 10^{-3}\end{array}$ & $\begin{array}{c}\text { Friction } \\
\text { Coefficient }\end{array}$ \\
\hline AISI -4140 & 510 & 8.48 & 117.26 & 0.92 \\
\hline Stellite12 & 190 & 1.25 & 6.44 & 0.93 \\
\hline
\end{tabular}

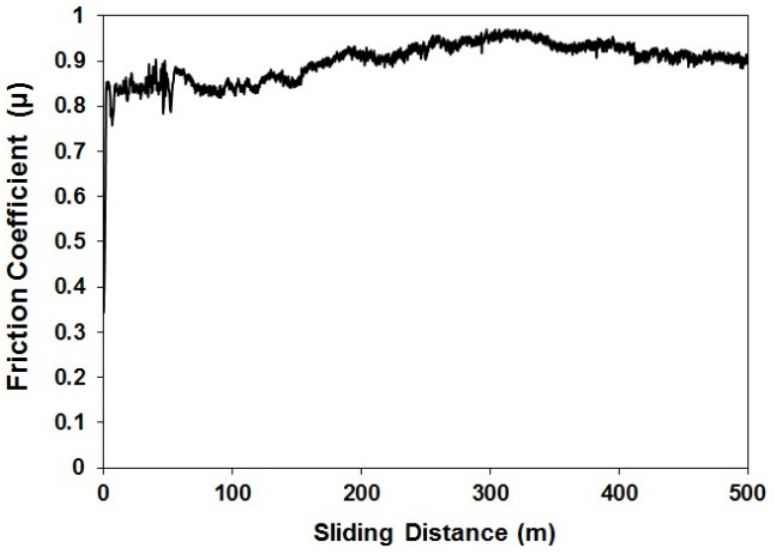

(a)

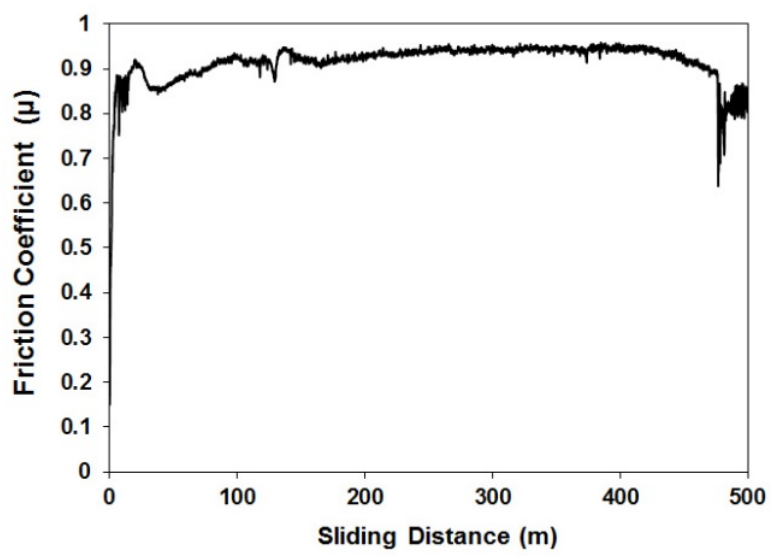

(b)

Figure 4. Friction coefficient curves of AISI 4140 steel and Stellite 12 coating tested at RT.

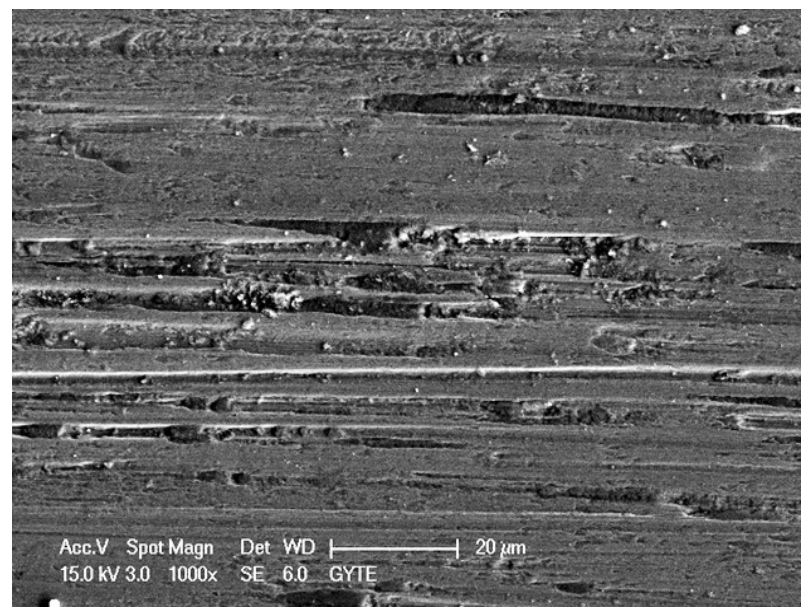

(a) 


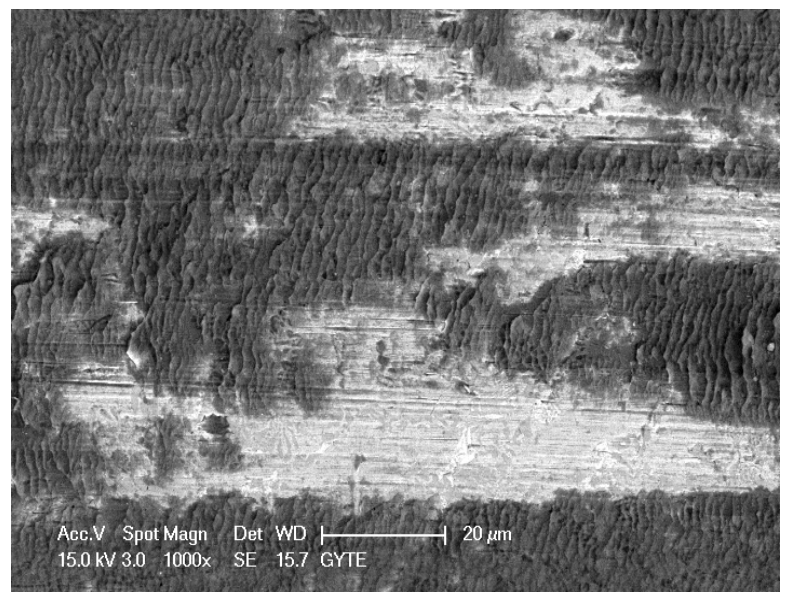

(b)

Figure 5. Worn surface micrographs of (a) AISI 4140 steel and (b) PTA deposited Stellite12 alloy after testing at RT.

\section{Conclusions}

In this study microstructures and wear resistance of Stellite 12 hardfacing alloy deposited by PTA machine on AISI 4140 steel were investigated. Stellite 12 alloy with carbon contents less than about $2 \mathrm{wt} \%$ exhibit a hypo-eutectic microstructure. The primary solidified phase in this alloy consists of a dendritic cobalt-rich solid solution phase with FCC $(\alpha-\mathrm{Co})$ and HCP $(\varepsilon-\mathrm{Co})$ crystal structure. The eutectic structure consists of cobalt-rich phase mixed with chromium-rich carbide $\left(\mathrm{Cr}_{7} \mathrm{C}_{3}, \quad \mathrm{Cr}_{23} \mathrm{C}_{6}\right)$, tungsten-containing complex carbide $\left(\mathrm{Co}_{3} \mathrm{~W}_{3} \mathrm{C}, \mathrm{Co}_{6} \mathrm{~W}_{6} \mathrm{C}\right)$ and intermetallic compounds $\left(\mathrm{Co}_{3} \mathrm{~W}, \mathrm{Co}_{7} \mathrm{~W}_{6}\right)$. Stellite 12 hardfacing coating exhibited superior wear resistance compared to AISI 4140 steel during dry sliding ball-on-disc wear test. Martensitic FCC to HCP transformation increased the Stellite 12's work hardening rate which was beneficial for sliding wear resistance of this alloy.

\section{Acknowledgements}

The authors would like to express their gratitude to Mr. Ahmet Nazim for carrying out SEM investigations and Senmak Co. for its technical support.

\section{REFERENCES}

[1] M. F. Buchely, J. C. Gutierrez, L. M. León, and A. Toro. The effect of microstructure on abrasive wear of hardfacing alloys, Wear, Vol. 259, 52-61, 2005.

[2] D. Chen, D. Liu, Y. Liu, H. Wang, and Z. Huang. Microstructure and fretting wear resistance of $\gamma / \mathrm{TiC}$ composite coating in situ fabricated by plasma transferred arc cladding, Surface and Coatings Technology, Vol. 239, 28-33, 2014.

[3] M. X. Yao, J. B. C. Wu, and Y. Xie. Wear, corrosion and cracking resistance of some $\mathrm{W}$ - or Mo-containing Stellite hardfacing alloys, Materials Science and Engineering: A, Vol. 407, 234-244, 2005.

[4] W. C. Lin and C. Chen. Characteristics of thin surface layers of cobalt-based alloys deposited by laser cladding, Surface and Coatings Technology, Vol. 200, 4557-4563, 2006.

[5] A. Khoddamzadeh, R. Liu, M. Liang, and Q. Yang. Novel wear-resistant materials-Carbon fiber reinforced low-carbon Stellite alloy composites, Composite: Part A, Vol. 43, 344-352, 2012.

[6] http://www.sulzer.com/

[7] W.O.Soboyejo and T.S.Srivatsan. Advanced Structural Materials: Properties, Design Optimization, and Applications, Taylor \& Francis Group Publications, USA, 2006.

[8] I. Radu and D. Y. Li. The wear performance of yttrium-modified Stellite 712 at elevated temperatures, Tribology International, Vol. 40, 254-265, 2007.

[9] J.C. Shin, J.M. Doh, J.K. Yoon, D.Y. Lee, and J.S. Kim. Effect of molybdenum on the microstructure and wear resistance of cobalt-base Stellite hardfacing alloys, Surface and Coatings Technology, Vol. 166, 117-126, 2013.

[10] C. D. Opris, R. Liu, M. X. Yao, and X. J. Wu. Development of Stellite alloy composites with sintering/HIPing technique for wear-resistant applications, Materials and Design, Vol. 28, 581-591, 2007.

[11] M.X. Yao, J.B.C. Wu, S. Yick, Y. Xie, R. Liu. High temperature wear and corrosion resistance of a Laves phase strengthened $\mathrm{Co}-\mathrm{Mo}-\mathrm{Cr}-\mathrm{Si}$ alloy, Materials Science and Engineering: A, Vol. 435-436, 78-83, 2006.

[12] P.J. Blau. Elevated-temperature tribology of metallic materials, Tribology International, Vol. 43, 1203-1208, 2010.

[13] I.A. Inman, P.S. Datta. Studies of high temperature sliding wear of metallic dissimilar interfaces IV: Nimonic 80A versus Incoloy 800HT, Tribology International, Vol. 44, 1902-1919, 2011. 